\title{
Correction to: Short-Term Prediction of Demand for Ride-Hailing Services: A Deep Learning Approach
}

\author{
Long Chen ${ }^{1} \cdot$ Piyushimita Vonu Thakuriah ${ }^{2} \cdot$ Konstantinos Ampountolas ${ }^{3}$
}

Published online: 27 May 2021

C) Springer Nature Singapore Pte Ltd. 2021

\section{Correction to: \\ Journal of Big Data Analytics in Transportation https://doi.org/10.1007/s42421-021-00041-4}

The publication of this article unfortunately contained a mistake. Table 1 and table 2 were identical.

The original article has been corrected.

Publisher's Note Springer Nature remains neutral with regard to jurisdictional claims in published maps and institutional affiliations.

The original article can be found online at https://doi.org/10.1007/ s42421-021-00041-4.

Long Chen

long.chen@glasgow.ac.uk

Piyushimita Vonu Thakuriah

p.thakuriah@rutgers.edu

Konstantinos Ampountolas

k.ampountolas@uth.gr

17 Lilybank Gardens, Glasgow, UK

2 Edward J. Bloustein School of Planning and Public Policy, Rutgers University, New Jersey 08901, USA

3 Department of Mechanical Engineering, University of Thessaly, 38334 Volos, Greece 